\title{
VIABILIDADE DO PÓLEN E DESENVOLVIMENTO DO TUBO POLÍNICO EM MACIEIRA (Malus spp.) ${ }^{1}$
}

\author{
ADRIANA CIBELE DE MESQUITA DANTAS ${ }^{2}$, MARIA LUISA PEIXOTO ${ }^{3}$, RUBENS ONOFRE NODARI ${ }^{4}$, \\ MIGUEL PEDRO GUERRA ${ }^{4}$
}

\begin{abstract}
RESUMO - No presente trabalho, estudaram-se características associadas à germinação in vitro e ao desenvolvimento in vivo do tubo polínico em seis variedades-copa e de porta-enxertos de macieira como subsídios para o estabelecimento de programas de melhoramento genético. Utilizou-se de pólen de seis cultivares de macieira inoculado em meio de cultura com ágar (10 g. $\left.\mathrm{L}^{-1}\right)$ em água destilada, combinados com concentrações de sacarose $\left(0 ; 10 ; 20 ; 30 ; 40\right.$ e 50\%) e ácido bórico $\left(0\right.$ e $\left.40 \mathrm{mg} . \mathrm{L}^{-1}\right)$. Para o estudo do desenvolvimento do tubo polínico, realizou-se coleta das flores em quatro períodos $(6 ; 12 ; 24$ e 48 horas após as polinizações) em M9 x Marubakaido e a autofecundação em M9, sendo os tubos polínicos analisados em coloração de azul de anilina acidificada/carmim acético e em fluorescência. A sacarose, em concentrações entre 15\% a 25\%, pode ser empregada com sucesso para a germinação in vitro de grãos de pólen da macieira. O ácido bórico não teve efeito positivo para esta característica. Na ausência do ácido bórico e na presença de 15\% de sacarose, observaram-se os maiores percentuais de germinação: Fuji (51,1\%), Imperatriz (31,7\%), M.9 (20,8\%), Catarina (19,2\%), Gala (13,7\%) e Marubakaido (6,1\%). Quanto ao desenvolvimento do tubo polínico, com 12 horas da polinização, iniciouse a germinação no pólen, no estigma, no cruzamento M.9 x Marubakaido, e após 24 horas da polinização observou-se $83 \%$ de germinação. As técnicas de coloração com azul de anilina acidificada com carmim acético e de visualização em fluorescência foram eficientes na visualização e coloração dos grãos de pólen e do desenvolvimento dos tubos polínicos.
\end{abstract}

Termos para indexação: Malus sp., pólen, sacarose, fluorescência

\section{GERMINATION OF POLLEN AND THE DEVELOPMENT OF POLLEN TUBES IN APPLE (Malus spp.)}

\begin{abstract}
In the present work it was studied features associated to the germination of pollen and the development of pollen tubes in six apple varieties as subsidies for the establishment of genetic improvement programs. Pollen grains were inoculated in culture medium with distilled water,

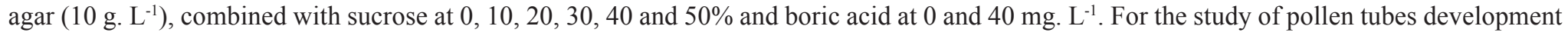
flowers were collected at 6, 12, 24 and 48 hours after antesis in M.9 x Marubakaido and in the self-pollinated M.9, being the pollen tubes analyzed in staining with blue aniline with acetic carmim and in fluorescence. Sucrose in concentrations ranging from $15 \%$ to $25 \%$ can successfully be used for the in vitro germination of pollen grains. Boric acid was not effective in promoting in vitro germination of pollen grains. In the absence of boric acid and in the presence of $15 \%$ of sucrose it was observed the largest germination rates: Fuji (51.1\%), Imperatriz (31.7\%), M.9 (20.8\%), Catarina (19.2\%), Gala (13.7\%), and Marubakaido (6.1\%). In the crossing M.9 x Marubakaido after 12 hours of pollination the pollen germination began in the stigma and after $24 \mathrm{hrs}$ it was observed $83 \%$ of germination. The techniques employed were efficient in the visualization and coloration of the pollen grains and of development of tube pollen.
\end{abstract}

Index terms: Malus sp., pollen, sucrose, fluorescence.

\section{INTRODUÇÃO}

A macieira (Malus spp) é uma fruteira que pertence à família Rosaceae, subfamília Pomoideae, gênero Malus. Malus $x$ domestica Borkh. é um híbrido interespecífico e M. sylvestris Mill., M. prunifolia Borkh. e $M$. baccata Borkh. estão envolvidas em diferentes graus no desenvolvimento da grande parte das variedades de macieira cultivadas (Korban, 1986). Entretanto, nos últimos anos, outras espécies de Malus têm contribuído para introdução de genes em macieiras cultivadas, via hibridação sexual, por meio de cruzamentos controlados ou ao acaso (Way et al., 1990). Os programas de melhoramento genético em macieira buscam a obtenção de novas cultivares para ampliar a base genética e com média a baixa exigência em frio e que, ao mesmo tempo, sejam polinizadoras compatíveis.

Na família Rosaceae, é comum a ocorrência de autoincompatibilidade na qual o tubo polínico expressa um dos alelos $S$ e, em contato com o pistilo, expressando este mesmo alelo, o desenvolvimento do tubo polínico é paralisado (Batlle et al., 1995; Broothaerts et al., 1995). A cultivar polinizadora deve apresentar coincidência do período de florescimento e compatibilidade do alelo $S$ com as plantas produtoras, além de produzir pólen viável (Neves et al., 1997; Certal et al., 1999). Uma vez que a análise da fertilidade do pólen é condição preliminar indispensável ao melhoramento genético clássico, dados sobre a viabilidade e o desenvolvimento de grãos de pólen são fundamentais para os estudos da biologia reprodutiva e para o desenvolvimento de programas de melhoramento genético desta espécie, pois permitem obter maiores sucessos nos cruzamentos (Flanklin et al., 1995).

Técnicas de microscopia permitem analisar características associadas à germinação dos tubos polínicos e suas taxas de crescimento, servindo também para analisar hibridações efetivas em programas de melhoramento genético e, assim, elucidar algumas formas de incompatibilidade (Kears \& Inouye, 1993). No presente trabalho, estudaram-se características associadas à germinação in vitro e ao desenvolvimento in vivo do tubo polínico em seis variedades-copa e de porta-enxertos de macieira como subsídios para o estabelecimento de programas de melhoramento genético.

\section{MATERIAL E MÉTODOS}

Os grãos de pólen foram obtidos a partir de anteras de 50 flores das cvs. copas Catarina, Imperatriz, Gala, Fuji e dos porta-enxertos Marubakaido e M.9, coletadas a campo, em estágio de balão, na E.E. São Joaquim, da Epagri/SC. Para a germinação do pólen in vitro, anteras foram depositadas em pequenas bandejas de papel, em estufa, cuja temperatura oscilou entre $20^{\circ} \mathrm{C}$ e $25^{\circ} \mathrm{C}$, durante 72 horas.

Em um primeiro ensaio, utilizou-se de sacarose (0 e $15 \%)$ e ácido bórico (0 e $\left.40 \mathrm{mg} . \mathrm{L}^{-1}\right)$ em meio de cultura com 10 g. $\mathrm{l}^{-1}$ de ágar dispensado em placas de petri ( $10 \mathrm{ml} /$ placa). No segundo ensaio, utilizouse dos grãos de pólen dos porta-enxertos Marubakaido e M.9 os quais

\footnotetext{
${ }^{1}$ (Trabalho 057/2005). Recebido: 10/03/2005. Aceito para publicação: 06/10/2005.

2 Eng. Agrônoma, Dr., Centro de Ciências Agrárias, Depto. Fitotecnia, UFSC, CEP: 88034-001, Florianópolis-SC. Fone. (0xx48) 331.5467. email:acmdantas@cca.ufsc.br.

${ }^{3}$ Bacharel em Química, Centro de Ciências Agrárias, Depto. Fitotecnia, UFSC, CEP: 88034-001, Florianópolis-SC.

${ }^{4}$ Eng. Agrônomo, Drs., Centro de Ciências Agrárias, Depto. Fitotecnia, UFSC, CEP: 88034-001, Florianópolis-SC.
} 
foram testados em seis concentrações de sacarose $(0 ; 10 ; 20 ; 30 ; 40$ e $50 \%$ ), porém isento de ácido bórico. Os grãos de pólen de cada cultivar foram aspergidos sobre a superfície do meio de cultura com auxílio de um pincel, e as culturas foram incubadas em $\mathrm{BOD}$ a $25^{\circ} \mathrm{C}$, por três horas. Decorrido este tempo, realizou-se a contagem da percentagem dos grãos de pólen germinados, considerando-se como tal aquele cujo comprimento tivesse ultrapassado o diâmetro do próprio grão de pólen. O delineamento experimental foi o inteiramente casualizado, com cinco repetições por tratamento.

Para o estudo do desenvolvimento do tubo polínico, realizaramse a polinização cruzada em M9 x Marubakaido e a autofecundação em M9. As polinizações foram realizadas em três pistilos por flor, emasculadas de cada cinco flores, em três árvores, constituindo três repetições. A coleta das flores foi feita em quatro períodos: $6 ; 12 ; 24$ e 48 horas após as polinizações. Imediatamente após a coleta das flores, os estiletes foram fixados em Carnoy (3 partes de etanol 95\%:1 parte de ácido acético glacial) e levados ao laboratório. Utilizou-se de duas técnicas de preparo de lâminas para a visualização dos tubos polínicos: a técnica de coloração com azul de anilina acidificada com carmim acético e a técnica de fluorescência. Para a técnica de anilina azul acidificada com carmin acético (Kears \& Inouye, 1993), cortaram-se os pistilos na base ou com os ovários intactos longitudinalmente, os quais foram corados sobre uma lâmina de vidro, por $10 \mathrm{~min}$, em uma gota de anilina azul acidificada $0,1 \%$ em $\mathrm{HCl} 1 \mathrm{~N}$, colocando-se a lamínula e observandose em microscópio Olympus BX40.

Para a técnica de fluorescência, colocaram-se os estiletes em placas de relógio com $\mathrm{NaOH} 8 \mathrm{~N}$ e, posteriormente, em estufa a $25^{\circ} \mathrm{C}$ por 10 a 15 minutos. Os estiletes foram depois lavados com água destilada por três vezes e mantidos na água até a sua transferência para uma lâmina com uma gota de solução de azul de anilina $0,1 \%$ em $\mathrm{K}_{3} \mathrm{PO}_{4}(0,1$ M). As observações foram feitas em microscópio invertido Olympus IMT-2, com aparato do epiflorescência, com filtros de $450 \mathrm{~nm}$. Foram observadas cinco lâminas para cada tratamento, contando-se o número de grãos de pólen germinados e o comprimento dos tubos polínicos encontrados em um determinado campo de visão.

\section{RESULTADOS E DISCUSSÃO}

\section{Germinação de pólen}

No primeiro ensaio, observou-se interação significativa entre os dois tratamentos. Na ausência de ácido bórico e de sacarose, a cv. Catarina apresentou maior percentagem $(15,7 \%)$ de germinação de grãos de pólen, seguida das cvs. Imperatriz (11,6\%), Gala (7,7\%), Fuji (6,8\%), M.9 (3,4\%) e Marubakaido (0,4\%). Na ausência do ácido bórico e na presença de $15 \%$ de sacarose, observou-se maior percentagem de germinação, quando comparada à ausência de sacarose. Os seguintes resultados foram observados: a cultivar Fuji apresentou a maior percentagem de germinação de pólen $(51,1 \%)$, seguida pela Imperatriz (31,7\%), M.9 (20,8\%), Catarina (19,2\%), Gala (13,7\%) e Marubakaido $(6,1 \%)$. Com $40 \mathrm{mg} \cdot \mathrm{L}^{-1}$ de ácido bórico, observou-se inibição na germinação do pólen em todas as cultivares testadas (Tabela 1). Nunes et al. (2001) observaram percentual de germinação menor na cultivar Fuji (20\%) quando utilizaram $10 \%$ de sacarose e 40 mg.L $\mathrm{L}^{-1}$ de ácido bórico. Em trabalho de Milutinovic et al. (1996), o ácido bórico apresentou efeito positivo nos resultados, com 64,2 e $88,3 \%$ para as cultivares Jonathan e Golden Delicious, respectivamente.

Os principais componentes do meio de germinação de pólen têm sido diferentes tipos e concentrações de açúcares e distintas concentrações de boro (Miranda \& Clement, 1990; Lorenzon \& Almeida, 1997). O carboidrato utilizado proporciona o equilíbrio osmótico entre o pólen e o meio de cultura e fornece energia para o desenvolvimento do tubo polínico (Stanley e Linskens, 1974). A adição de boro ao meio de cultura mostra respostas variáveis conforme a espécie, e seu mecanismo de ação consiste em interagir com o açúcar e formar um complexo ionizável açúcar-borato, o qual reage mais rapidamente com as membranas celulares (Pfahler, 1967; Askin et al., 1990). Diferenças em relação ao comprimento do tubo polínico foram observadas nas cvs. Catarina e Imperatriz e no porta-enxerto M.9 e na presença de 15\% de sacarose e ausência de ácido bórico, os quais apresentaram maior comprimento comparativamente àquele verificado na presença do ácido bórico (Figura 1).

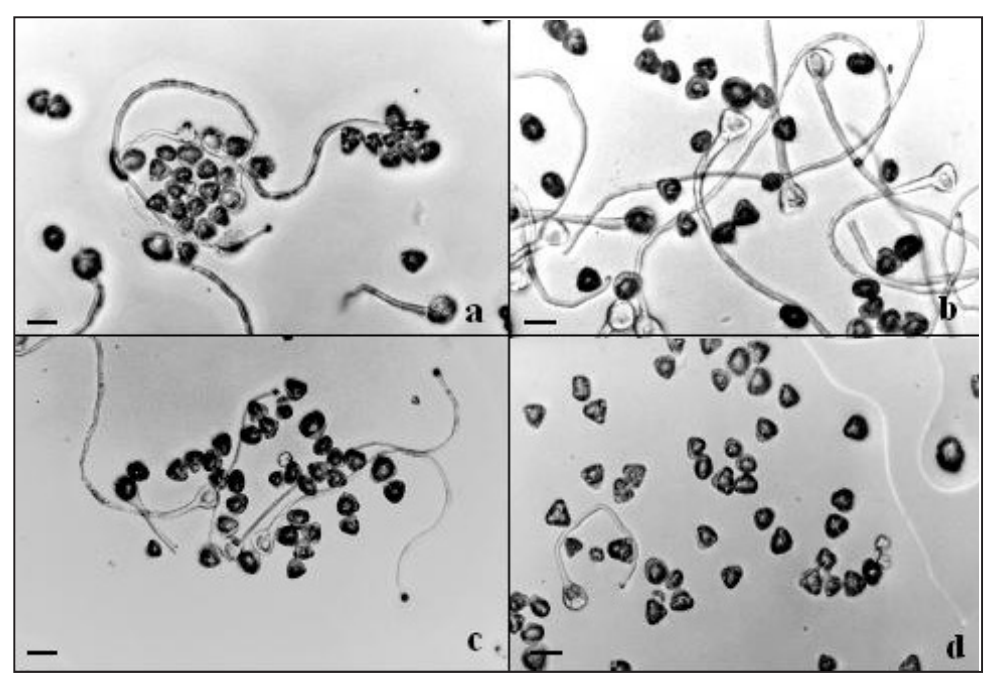

FIGURA 1 - Crescimento dos tubos polínicos das cultivares: a) Catarina - ác. Bórico (0 mg. $\left.\mathrm{L}^{-1}\right)$ e sacarose (15\%); b) Imperatriz - ác. Bórico (0 mg.L $\left.\mathrm{L}^{-1}\right)$ e sacarose (15\%); c) M.9 - ác. Bórico (0 mg.L $\left.L^{-1}\right)$ e sacarose (15\%); d) M.9 - ác. Bórico (40 mg.L $\left.{ }^{-1}\right)$ e sacarose (15\%). Barra: $88 \mu \mathrm{m}$.

No segundo ensaio, os resultados obtidos mostraram que as diferentes concentrações de sacarose promoveram modificações significativas na taxa de germinação dos grãos de pólen das cvs avaliadas. Grãos de pólen do porta-enxerto M.9 apresentaram germinação superior àquela do porta-enxerto Marubakaido. Houve aumento gradativo na germinação até a concentração de $20 \%$ de sacarose e redução na taxa de germinação em meio de cultura contendo $50 \%$ de sacarose (Figura 2). Esses resultados são similares àqueles observados por Raseira e Raseira (1996) em grãos de pólen de araçazeiro.

\section{Desenvolvimento do tubo polínico}

A proporção de grãos de pólen observada entre os sistemas de polinização foi bastante diferenciada e também quanto ao período de coleta após a polinização. Em coletas realizadas 6 horas após as

TABELA 1 - Taxas de germinação in vitro de grãos de pólen de macieira em diferentes concentrações de sacarose e ácido bórico.

\begin{tabular}{|c|c|c|c|c|}
\hline \multirow{2}{*}{ Cultivares } & \multicolumn{2}{|c|}{ Ac. bórico $\left(\mathrm{mg} . \mathrm{L}^{-1}\right) /$ Sacarose $\left(\mathrm{g} . \mathrm{L}^{-1}\right)$} & \multicolumn{2}{|c|}{ Ac. bórico $\left(\mathrm{mg} . \mathrm{L}^{-1}\right) /$ Sacarose $\left(\mathrm{g} . \mathrm{L}^{-1}\right)$} \\
\hline & $0 / 0$ & $40 / 0$ & $0 / 150$ & $40 / 150$ \\
\hline Catarina & 15,7 a $B$ & $0 \mathrm{a} \mathrm{C}$ & $19,2 \mathrm{~d} \mathrm{~A}$ & $0 \mathrm{a} \mathrm{C}$ \\
\hline Imperatriz & $11,6 \mathrm{~b} \mathrm{~B}$ & 0 a $\mathrm{C}$ & $31,7 \mathrm{~b} \mathrm{~A}$ & 0 a $\mathrm{C}$ \\
\hline Gala & 7,7 c B & 0 a $\mathrm{C}$ & $13,7 \mathrm{c} \mathrm{A}$ & $0 \mathrm{a} \mathrm{C}$ \\
\hline Fuji & $6,8 \mathrm{~d} B$ & 0 a $\mathrm{C}$ & 51,1 a $\mathrm{A}$ & 0 a $\mathrm{C}$ \\
\hline M.9 & 3,4 e $B$ & 0 a $\mathrm{C}$ & $20,8 \mathrm{cA}$ & 0 a $\mathrm{C}$ \\
\hline Marubakaido & $0,4 \mathrm{f} \mathrm{B}$ & 0 a $\mathrm{C}$ & $6,1 \mathrm{f} \mathrm{A}$ & 0 a $\mathrm{C}$ \\
\hline
\end{tabular}

Médias com letras iguais, minúsculas nas linhas e maiúsculas nas colunas, não diferem entre si, pelo teste de SNK, a 5\% de probabilidade. 
polinizações, não foram observados grãos de pólen germinados. A partir das 12 horas, $30 \%$ dos grãos de pólen iniciaram a germinação no cruzamento M.9 x Marubakaido, e seus tubos polínicos apresentaram comprimento médio de 16,65 $\mu \mathrm{m}$. Após 24 horas da polinização, foi observada $83 \%$ de germinação com tubos polínicos de até $528 \mu \mathrm{m}$ de comprimento (Tabela 2, Figuras 3A, 3B). Na autofecundação de M.9, depois de 24 e 48 horas da polinização, observaram-se taxas de $6,25 \%$ e $6,45 \%$ de germinação de pólen, respectivamente. O diâmetro médio do grão de pólen foi de $16,65 \mu \mathrm{m}$ e o do ovário, em torno de $616 \mu \mathrm{m}$ (Figura 3C e 3D).

- M9 • Marubakaido

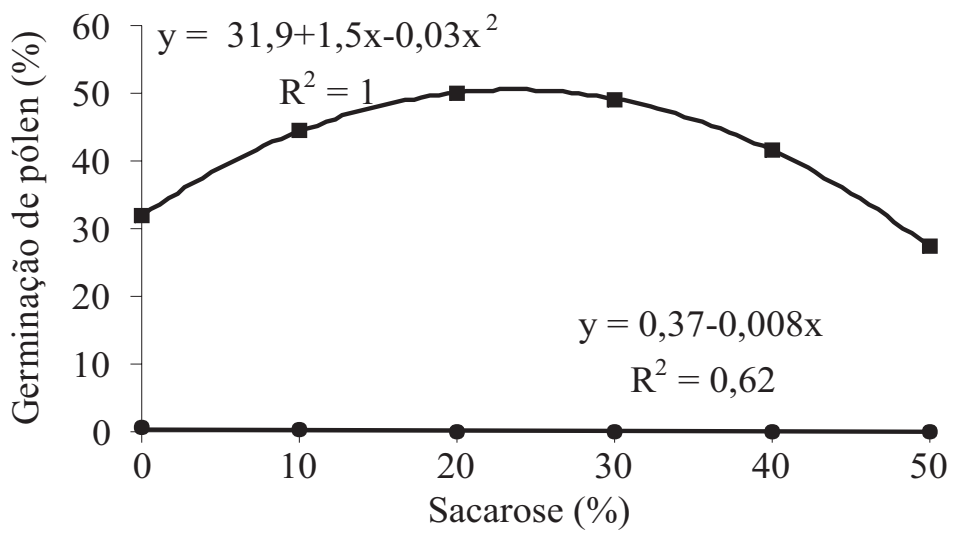

FIGURA 2 - Germinação de pólen in vitro dos porta-enxertos de macieira Marubakaido e M.9 em resposta a diferentes concentrações de sacarose.

Em relação ao protocolo para visualização de tubos polínicos, a utilização de lâminas coradas com a técnica de anilina azul/carmin acético permitiu a obtenção de bom contraste entre o pólen germinado e o estigma, pois o carmin acético corou de escuro os tubos polínicos (Figura 3A). Contudo, a fluorescência mostrou-se mais eficiente quanto à intensidade e visibilidade dos grãos de pólen (Figura 3B). Na autofecundação do porta-enxerto M.9, foi observada a permanência de grãos de pólen na parte apical do estilo, presos às papilas estigmáticas (Figura 3E/F), evidenciando assim que a barreira de incompatibilidade ocorreu na parte apical do estilo. Este fato foi também constatado com a cv. StarKrimson, onde menos de 1\% dos tubos polínicos alcançaram a base do estilo 48 horas após a polinização (Moltalti e Filiti, 1984). A auto-incompatibilidade pode agir em três estágios, inicialmente inibindo a germinação de grãos de pólen e do crescimento de tubo de polínico, ou causando aborto de embriões (Weller \& Ornduff, 1989).

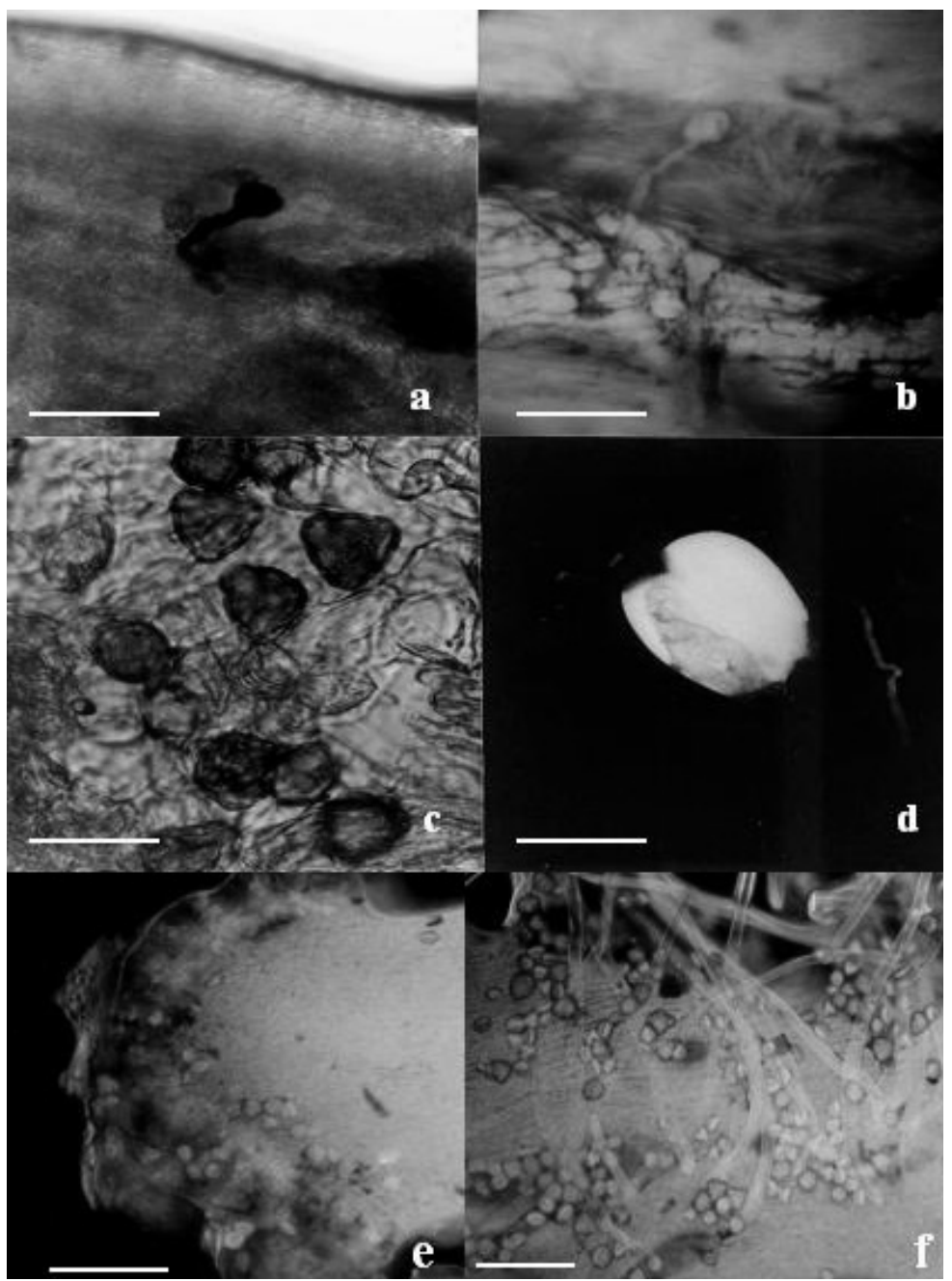

FIGURA 3 - Desenvolvimento dos tubos polínicos: a) 12 horas após a polinização, barra: $44 \mu \mathrm{m}$ técnica de azul de anilina acidificada/carmin acético; b) 24 horas após a polinização, barra: $44 \mu \mathrm{m}$, fluorescência; c) diâmetro do pólen, barra: $22 \mu \mathrm{m}$; d) ovário, barra: $22 \mu \mathrm{m}$, ef) localização apical dos grãos de pólen, barra: $88 \mu \mathrm{m}$.

TABELA 2 - Número médio de grãos de pólen observados e germinados, com a utilização da técnica de azul de anilina acidificada/carmin acético.

\begin{tabular}{ccccc}
\hline Polinização & Período de coleta & Grãos de pólen observados & Grãos de pólen germinados & (\%) Grãos de pólen germinados \\
\hline \multirow{3}{*}{ M.9 x Marubakaido } & 6 & 14 & 0 & 0 \\
& 12 & 34 & 12 & 30 \\
& 24 & 25 & 20 & 83 \\
M.9 autofecundada & 48 & 24 & 18 & 75 \\
& 12 & 22 & 0 & 0 \\
& 24 & 32 & 2 & 0 \\
& 48 & 24 & 2 & 6,25 \\
\end{tabular}

\section{CONCLUSÕES}

Em relação à germinação dos grãos de pólen nas cultivares testadas, a sacarose em concentrações entre $15 \%$ a $25 \%$ pode ser empregada com sucesso para a germinação in vitro de grãos de pólen da macieira. O ácido bórico não teve efeito positivo para essa característica. A partir de 12 horas da polinização, inicia-se a germinação no pólen, no estigma. A duas técnicas empregadas neste trabalho, de coloração com carmin acético e de fluorescência, foram eficientes na visualização e coloração dos grãos de pólen e de tubos polínicos.

\section{REFERÊNCIAS}

ASKIN, A.; HEPAKSOY, S.; OZCAGIRAN, R. Investigations on the effects of gibberellic acid and boric acid on the germination of some sweet cherry pollens. Ege Universite Ziraat Fakultesi Dergise, Dergise, v. 27, n. 03, p.105-116, 1990.

BROOTHAERTS, W.; JANSSENS, G.A.; PROOST, P.; BROKAERT, W.F. cDNA cloning and molecular analysis of two self-incompatibility alleles from apple. Plant Molecular Biology, Dordrecht, v.27, p.499511,1995

BATLLE, I.; ALSTON, F.H.; EVANS, K.M. The use of the isoenzymic 
marker gene Got -1 in the recognition of incompatibility $S$ alleles in apple. Theoretical and Applied Genetics, Berlin, v.90, p. 303-306, 1995.

CERTAL, A.C.; SANCHEZ, A.M.; KOKKO, H.; BROOTHAERTS, W.; OLIVEIRA, M.M.; FEIJÓ, J.A. S-Rnases in apple are expressed in the pistil along the pollen tube growth path. Sexual Plant Reprodution, Heidelberg, v.12, p.94-98, 1999.

FLANKLIN, F.H.C.; LAWRENCE, M.J.; FLANKLIN-TONG, V.E. Cell and molecular biology of self-incompatibility in flowering plants. International Review of Cytology, v.158, p.1-62, 1995.

KEARS, C. A.; INOUYE, D. W. Techniques for pollination biologists. Niwot: University Press of Colorado, 1993.

KORBAN, S.S. Interspecific hyridization in Malus. HortScience, Alexandria, v.21, p.41-48, 1986.

LORENZON, M.C.A.; ALMEIDA, E.C. de. Viabilidade e germinação do pólen de linhagens parentais de cebola híbrida. Pesquisa Agropecuária Brasileira, Brasília, v.32, n.4, p.345-349, 1997.

MIRANDA, P.A.; CLEMENT, C.R. Germination and storage of pejibaye (Bactris gasipaes) Palmae pollen. Revista de Biologia Tropical, San Jose, v. 38, n. 01, p.29-33, 1990.

MOLTALTI, P.; FILITI, N. Mentor pollen effect on the in vivo germination of self-incompatible apple pollen. Science Horticulturae, Amsterdan, v.23, p.337-342, 1984.

MILUTINOVIC, M.; MOMIROVIC, G.S.; NIKOLIC, D. Functionality of poll and fruit set in apples. Acta Horticulturae, Wageningen, v. 423, p. 167-169, 1996.
NEVES, T.S.; MACHADO, G.M.E.; OLIVEIRA, R.P. Efeito de diferentes concentrações de carboidratos e ácido bórico na germinação de grãos de pólen de cubiuzeiro e cupuaçuzeiro. Revista Brasileira de Fruticultura, Cruz das Almas, v.19, n.2, p.— ,1997.

NUNES, J.C.O.; DANTAS, A.C.M.; PEDROTTI, E.L.; ORTH, A.I.; GUERRA, M.P. Germinação de pólen in vitro e receptividade do estigma em macieira cvs. Fuji e Goldeen Delicious. Revista Brasileira de Fruticultura, Jaboticabal, v. 23, n.1, p. 35-39, 2001.

PFAHLER, P.L. In vitro germination and pollen tube growth of maize (Zea mays L.) pollen; calcium and boron effects. Canadian Journal of Botany, Toronto, v. 45, p.839-845, 1967.

RASEIRA, M.C.B.; RASEIRA, A. Contribuição ao estudo do araçazeiro, Psidium catteyanum.Pelotas: Embrapa/CPACT, 1996. p.33-45.

STANLEY, R.G.; LINSKENS, H.F. Pollen: biology, biochemistry and management. New York: Springer-Verlag, 1974. 172p.

WELLER, S.G.; ORNDUFF, R. Incompatibility in Amsinckin grandiflora (Boraginaceae): Distribution of callose plugs and pollen tubes following inter- and intramorph crosses. American Journal of Botany, Toronto, v. 76, n.2, p. 277-282.1989.

WAY, R.D.; ALDWINCKLE, H.S.; LAMB, R.C.; REJMAN, A.; SANSAVANI, S.; SHEN, T; WATKINS, R.; WESTWOOD, M.N.; YOSHIDA, T. Apples (Malus). In: MOORE, J.N.; BALLINGTON, J.R. (Ed.). Genetics resources of temperate fruit and nut crops. Wageningen: International Society for Horticultural Science, 1990. p.1.62. 